\title{
The Association between Weather Conditions (Ambient Air Temperature and Relative Humidity) with Coronavirus Disease (COVID-19) Risk in Bandar Abbas, Iran
}

\author{
Yadolah Fakhri ( YA.FAKHRI@GMAIL.COM ) \\ Hormozgan University of Medical Sciences \\ Mostafa Hadei \\ Tehran University: University of Tehran \\ Ali Rostami \\ Babol University of Medical Science \\ Ali Mouseli \\ Hormozgan University of Medical Sciences
}

\section{Research Article}

Keywords: SARS-CoV-2, Weather, COVID-19, Temperature, Humidity

Posted Date: September 7th, 2021

DOl: https://doi.org/10.21203/rs.3.rs-864631/v1

License: (c) (i) This work is licensed under a Creative Commons Attribution 4.0 International License.

Read Full License 


\section{Abstract}

Background: This study was devoted to evaluate the association between COVID-19 infection and weather conditions in Bandar Abbas, Iran.

Methods: The positive cases data was retrieved from the Ministry of Health and Medical Education of Iran (MOHME) and weather conditions from the Iran meteorological organization (IMO) from the 01, October 2020 to 27, November 2020. The components of weather consist of average of the ambient air temperature $\left({ }^{\circ} \mathrm{C}\right)$ and relative humidity $(\%)$. The Spearman correlation test was used to determine the association between weather conditions (temperature and relative humidity) with COVID-19 infection.

Results: Spearman analysis showed that air temperature (Coefficient $=-0.303$ and P-value $=0.001$ ) were negatively associated with COVID-19 infection. However, no significant association was observed between relative humidity (Coefficient $=0.088$ and P-value $=0.340$ ) and COVID-19 infection. Hence, the ambient air temperature can be considered as a considerable variable in the COVID-19 infection in Bandar Abbas.

Conclusions: The results of this study can be used for prevention and control of COVID-19 infection in areas with similar meteorological conditions in world.

\section{Background}

The severe acute respiratory syndrome coronavirus 2 (SARS-CoV-2) was observed in Wuhan, China on 31 December 2019 [1-3]. The 2019 novel coronavirus disease (COVID-19) declared as a pandemic by World Health Organization (WHO) on March 11, 2020 [4, 5]. As of 1 May, 2020, more than 3,292,489 positive cases and about 233,144 death cases have been reported [6].

The studies shows that COVID-19 can be less risk than severe acute respiratory syndrome (SARS) and middle east respiratory syndrome (MERS) [1, 2]. However, COVID-19 is more contagious than both SARS and MERS [5, 7].

The clinical symptoms of COVID-19 consist of coughing, shortness of breath,and fever [8]. The period from the onset of COVID-19 signs and symptoms to the outcome (death or recovery) can be from 6 to 41 days with an average of 14 days $[9,10]$. This period is dependent on the immune system and age of the patients [10]. In severe cases of the disease, COVID-19 infection can cause kidney failure, pneumonia, and even death [11]. The clinical signs of severe cases are like to the symptoms of MERS and SARS [12].

The first confirmed cases of COVID-19 were observed in Qom on 19 February, 2020 [13]. Then COVID-19 infection spread other areas of Iran consists of Tehran, Markazi, Isfahan, and Semnan [14]. In Hormozgan province, the first confirmed case of COVID-19 was observed in Qeshm on February 23, 2020 and following other confirmed cases were observed in the other areas of the Hormozgan province. 
The long-term climate change could affect the emission of the Nile virus in Europe and US [15]. Also, the weather conditions can be one of the main effective variables on respiratory diseases such as MERS and SARS [16]. Optimal wind speed, relative humidity, and air temperature are weather components that can affect the survival of the SARS-Coronavirus $[17,18]$.

Although several studies have shown the association between weather conditions and respiratory disease $[15-17,19,20]$ but due to the uncertain behavior of SARS-CoV-2[21], more research is needed. The aim of this study was to evaluate the association between COVID-19 infection and weather conditions (air temperature and relative humidity) in Bandar Abbas, Iran.

\section{Material And Method \\ 2.1. Study area}

The coastal city of Bandar Abbas is the capital of Hormozgan province in the south of Iran with geographical coordinates of $27^{\circ} .1837 \mathrm{~N}$ latitude and $56^{\circ} .2774 \mathrm{E}$ longitude [22]. The area of Bandar Abbas city consists of $45 \mathrm{Km}^{2}$ with the height of $10 \mathrm{~m}$ above open sea [23]. The population of this city was 526,648 inhabitants based on the latest population census in 2017 [24]. In addition, the average air temperature of Bandar Abbas city is $26.9^{\circ} \mathrm{C}$ with $64.8 \%$ relative humidity and $182.1 \mathrm{~mm} /$ year precipitation [25].

\subsection{Data collection}

COVID-19 infection was diagnosed based on the World Health Organization (WHO) protocols [26] using RT-PCR assay of pharyngeal swab and nasal samples [5,27]. Collected samples were transferred to the COVID-19 laboratory in the Ministry of Health and Medical Education (MOHME) in Tehran. The results of COVID-19 diagnostic tests were transmitted to HUMS center through an integrated health information system (IHIS, http://bi.hums.ac.ir/reports/powerbi/MCMC), continuously. The number of positive cases per day was recorded from 01, October 2020 to 27, November 2020. In addition, the weather data were retrieved from 01, October 2020 to 27, November 2020 from the meteorological organization in Bandar Abbas. The weather data consist of average of air temperature $\left({ }^{\circ} \mathrm{C}\right)$ and relative humidity $(\%)[28]$.

\subsection{Data analysis}

Kolmogorov-Smirnov test shows that data were not normal distribution. As distribution of our data was not normal, therefore spearman correlation analysis was used to determine the association between daily positive cases of COVID-19 and the weather conditions. Statistical analysis was conducted using IBM SPSS software version 20.0 (Chicago, IL, USA). The P-value $<0.05$ was considered as statistical significant.

\section{Results And Discussion}


This study investigated the association between weather conditions including air temperature, and relative humidity with the confirmed cases of COVID-19 infection (Table 1s). The trend of changes in the positive cases of COVID-19 infections, ambient air temperature and relative humidity was presented in Fig. 1. Two major peaks of COVID-19 cases were observed in 15th October $(n=22$ cases) and 8th November ( $n=20$ cases). The overall trend of confirmed cases is increasing over study period. However as expected small fluctuations can be observed. In case of Temperature, the overall trend is decreasing from the peak at $37.3^{\circ} \mathrm{C}$ (5th August) to the lowest values around $21.2^{\circ} \mathrm{C}$ (25th November). In case of $\mathrm{RH}$, some large fluctuations were detected, namely in 30th August - 5th September, 9th September - 26th September, and 10th October - 1st November. The total number of positive cases COVID-19 infection was 1041 in Bandar Abbas during the study period. In addition, the averages of air temperature, and relative humidity were $30.04 \pm 4.34^{\circ} \mathrm{C}$ and $53.18 \pm 17.93 \%$, respectively (Table 1 ). These results show that Bandar Abbas has a warm and humid climate.

Table 1

Spearman coefficients between positive cases of Covid-19 infection with weather variables.

\begin{tabular}{|llll|}
\hline Weather variables & Mean \pm SD & Coefficient & P value \\
\hline Ambient air temperature $\left({ }^{\circ} \mathrm{C}\right)$ & $30.04 \pm 4.34$ & -0.303 & 0.001 \\
\hline Relative humidity $(\%)$ & $53.18 \pm 17.93$ & 0.088 & 0.340 \\
\hline
\end{tabular}

The Spearman correlation analysis shows that there was a significant association between the daily number of confirmed cases of COVID-19 and ambient air temperature (Coefficient $=-0.303$ and P-value $=$ 0.001) (Table 1 and Fig. 2A). In case of relative humidity, no significant correlation with daily number of COVID-19 cases was observed (Coefficient $=0.088$ and P-value $=0.340)$ (Table 1 and Fig. 2B). These results show that ambient air temperature can negatively affect the spread of COVID-19, i.e. with increasing air temperature, a decrease in number of COVID-19 cases could be expected. While, increasing relative humidity can increase the daily confirmed cases of the disease.

Our findings are consistent with some other studies. In a study conducted on 31 provincial-level regions in China, using a distributed lag non-linear model (DLNM), the authors found that although higher temperatures directly affected the number of COVID-19 cases in some regions, the association in most of the areas and also in the whole country was negative, indicating a reduction in positive cases of COVID19 after the incidence of high temperatures (RR: 0.96, 95\% Cl: 0.93-0.99). In the same study, a significant negative association was found between temperature and relative risk of COVID-19 infection in mainland China (Coefficient $=-0.0100,95 \% \mathrm{Cl}:-0.0125,-0.0074$ ) [29]. In another study on 11 cities of China, temperature and humidity negatively associated with the transmissibility of COVID-19 ( P-value $<0.001$ ) [30]. In a study of 430 cities around the world for 52 days, a meteorological model was able to predict the global outbreak with a high association $\left(R^{2}>0.6\right)$ [31]. Despite our study, a study in Indonesia showed that the average air temperature has a positive significant association with the daily positive cases of COVID-19, indicating an increase in the number of positive cases with the increase in temperature. The 
association was also positive for other weather variables including minimum and maximum temperature, relative humidity, and rainfall [32]. In a study of Wuhan, the mortality of COVID-19 was associated with temperature positively $(R=0.44)$ and with relative humidity negatively $(R=-0.32)$ [33].

The contradiction between the results of studies may be due to the range of temperature and $\mathrm{RH}$ observed in each place. An analysis of 122 Chinese cities shows that the association between COVID- 19 and ambient air temperature was approximately linear in the range of $\angle 3^{\circ} \mathrm{C}$. When ambient air was less than $3^{\circ} \mathrm{C}$, each $1^{\circ} \mathrm{C}$ rise temperature was associated with a $4.86 \%(95 \% \mathrm{Cl}: 3.21-6.51)$ increase in positive cases of COVID-19 [18]. In another study, the spread of the virus showed a strong association within the $4-12^{\circ} \mathrm{C}$ mean daily air temperature [34]. Shi et al. (2020) considering 31 provincial-level regions in China reported that the association between daily cases of COVID-19 and air temperature is biphasic (with a peak at $10^{\circ} \mathrm{C}$ ). For temperatures higher than $10^{\circ} \mathrm{C}$, a decrease in the number of positive cases was observed; while, with increasing temperature up to $10^{\circ} \mathrm{C}$, positive cases increased [29].

There are many other factors that can potentially affect the spread of COVID-19 infection, and interfere with the effect of weather [32]. This is probably why the results of relevant studies contradict. First, the mobility of the population i.e. entry and exit into the city can change the daily number of positive cases. Second, the change in individual health parameters consist of use of hand sanitizers and hand washing habits due to education could alter the trends. Third, there are other weather variables such as visibility and atmospheric variables such as ultra-violet (UV) radiation that are included in other studies [31, 34], but these data were not accessible. And last but not the least, socio-economic development, urbanization ,population immunity, and level can all be other affecting factors [35].

To draw a conclusion whether meteorological parameters such as temperature and humidity can affect the spread of SARS-CoV-2, more comprehensive studies with longer study periods and broader study areas are required. Since the SARS-CoV-2 is novel, current evidence stands only on data recorded during a few months and from some limited areas. Therefore, the results of this study and similar ones should be used conservatively. In addition, the association between weather conditions and the number of positive cases of COVID-19 could be non-linear. Therefore, investigating a limited range of temperatures and also other variables could lead to different results.

\section{Conclusions}

In this study, the association between COVID-19 infection and weather (temperature and humidity) was investigated in Bandar Abbas, Iran. Air temperature, but not relative humidity, was significantly associated with daily number of COVID-19 confirmed cases. Therefore, weather conditions can be considered as an important variable in COVID-19 spread in Bandar Abbas and areas with similar meteorological conditions. Findings of this study can be used for the prevention and control of COVID-19 infection in the world.

\section{Declarations}




\section{Ethics approval}

Ethical approval was approved from the Hormozgan University of medical sciences Ethics Committee (IR.HUMS.REC.1398.471).

\section{Consent to participate}

Not applicable.

\section{Consent to Publish}

Not applicable.

\section{Authors Contributions}

Study design was conducted by Yadolah Fakhri and Ali Mouseli; Analysis of data by Mostafa Hadei and Ali Rostami,; Prepare manuscript by Yadolah Fakhri, Mostafa Hadei and Ali Mouseli.

\section{Acknowledgements}

The Authors extend their thanks to Infectious and Tropical Diseases Research Center, Hormozgan Health Institute, Hormozgan University of Medical Sciences for the financial grants of this study (IR.HUMS.REC.1398.471).

\section{Funding}

Infectious and Tropical Diseases Research Center, Hormozgan Health Institute, Hormozgan University of Medical Sciences for the financial grants of this study (IR.HUMS.REC.1398.471).

\section{Availability of data and materials}

Data openly available in a public repository

\section{Conflict of interest}

The authors declare that there is no conflict of interests. 
1. Surveillances V. The Epidemiological Characteristics of an Outbreak of 2019 Novel Coronavirus Diseases (COVID-19)-China, 2020. China CDC Weekly. 2020;2(8):113-22.

2. Chan JF-W, Yuan S, Kok K-H, To KK-W, Chu H, Yang J, Xing F, Liu J, Yip CC-Y, Poon RW-S. A familial cluster of pneumonia associated with the 2019 novel coronavirus indicating person-to-person transmission: a study of a family cluster. The Lancet. 2020;395(10223):514-23.

3. Chen H, Guo J, Wang C, Luo F, Yu X, Zhang W, Li J, Zhao D, Xu D, Gong Q. Clinical characteristics and intrauterine vertical transmission potential of COVID-19 infection in nine pregnant women: a retrospective review of medical records. The Lancet. 2020;395(10226):809-15.

4. Zhu N, Zhang D, Wang W, Li X, Yang B, Song J, Zhao X, Huang B, Shi W, Lu R. A novel coronavirus from patients with pneumonia in China, 2019. New England Journal of Medicine 2020.

5. Huang C, Wang Y, Li X, Ren L, Zhao J, Hu Y, Zhang L, Fan G, Xu J, Gu X. Clinical features of patients infected with 2019 novel coronavirus in Wuhan, China. The Lancet. 2020;395(10223):497-506.

6. Worldometers. COVID-19 CORONAVIRUS PANDEMIC. https://www.worldometers.info/coronavirus/ Last updated: April 27, 2020, 08:43 GMT. 2020.

7. Paules $\mathrm{Cl}$, Marston HD, Fauci AS. Coronavirus infections-more than just the common cold. Jama. 2020;323(8):707-8.

8. Huang C, Wang Y, Li X, Ren L, Zhao J, Hu Y, Zhang L, Fan G, Xu J, Gu X, et al. Clinical features of patients infected with 2019 novel coronavirus in Wuhan, China. The Lancet. 2020;395(10223):497506.

9. Wang W, Tang J, Wei F. Updated understanding of the outbreak of 2019 novel coronavirus (2019nCoV) in Wuhan, China. J Med Virol. 2020;92(4):441-7.

10. Rothan HA, Byrareddy SN. The epidemiology and pathogenesis of coronavirus disease (COVID-19) outbreak. J Autoimmun. 2020;109:102433.

11. Rothan HA, Byrareddy SN. The epidemiology and pathogenesis of coronavirus disease (COVID-19) outbreak. J Autoimmun 2020:102433.

12. Wang $Y$, Wang $Y$, Chen $Y$, Qin Q. Unique epidemiological and clinical features of the emerging 2019 novel coronavirus pneumonia (COVID-19) implicate special control measures. J Med Virol. 2020;92(6):568-76.

13. Takian A, Raoofi A, Kazempour-Ardebili S. COVID-19 battle during the toughest sanctions against Iran. The Lancet 2020.

14. Abdi M. Coronavirus disease 2019 (COVID-19) outbreak in Iran; actions and problems. Infection Control \& Hospital Epidemiology 2020:1-5.

15. Epstein PR. West Nile virus and the climate. J Urban Health. 2001;78(2):367-71.

16. Tosepu R, Gunawan J, Effendy DS, Lestari H, Bahar H, Asfian P. Correlation between weather and Covid-19 pandemic in Jakarta, Indonesia. Sci Total Environ 2020:138436.

17. Yuan J, Yun H, Lan W, Wang W, Sullivan SG, Jia S, Bittles AH. A climatologic investigation of the SARS-CoV outbreak in Beijing, China. Am J Infect Control. 2006;34(4):234-6. 
18. Zhu Y, Xie J. Association between ambient temperature and COVID-19 infection in 122 cities from China. Sci Total Environ 2020:138201.

19. Bull G. The weather and deaths from pneumonia. The Lancet. 1980;315(8183):1405-8.

20. Dalziel BD, Kissler S, Gog JR, Viboud C, Bjørnstad ON, Metcalf CJE, Grenfell BT. Urbanization and humidity shape the intensity of influenza epidemics in US cities. Science. 2018;362(6410):75-9.

21. Neher RA, Dyrdak R, Druelle V, Hodcroft EB, Albert J. Potential impact of seasonal forcing on a SARSCoV-2 pandemic. Swiss Med Wkly 2020, 150(1112).

22. Nabizadeh R, Sajadi M, Rastkari N, Yaghmaeian K. Microplastic pollution on the Persian Gulf shoreline: A case study of Bandar Abbas city, Hormozgan Province, Iran. Mar Pollut Bull. 2019;145:536-46.

23. Saeedi H. Availability of Venerid Clam, Amiantis umbonella as potential metal bioindicator in Bandar Abbas coast, the Persian Gulf. The Egyptian Journal of Aquatic Research. 2012;38(2):93-103.

24. SCIR. Statistical Center of Iran. Iranian Census in 2017. https://www.amar.org.ir/english. In.; 2017.

25. IRIMO: Iran Meteorological Organization. Climate of Hormozgan province. http://irimo.ir/eng/index.php In.; 2020.

26. WHO: World Health Organization. Clinical management of severe acute respiratory infection when novel coronavirus (2019-nCoV) infection is suspected: interim. guidance. January 28. 2020 https://www.who.int/docs/default-source/coronaviruse/ clinical-management-of-novel-cov.pdf. In.; 2020.

27. Guan W-j, Ni Z-y, Hu Y, Liang W-h, Ou C-q, He J-x, Liu L, Shan H. Lei C-I, Hui DS: Clinical characteristics of coronavirus disease 2019 in China. New England Journal of Medicine 2020.

28. Iran Meteorological Organization. http://www.irimo.ir/eng/index.php.

29. Shi P, Dong Y, Yan H, Zhao C, Li X, Liu W, He M, Tang S, Xi S. Impact of temperature on the dynamics of the COVID-19 outbreak in China. Sci Total Environ. 2020;728:138890.

30. Guo X-J, Zhang H, Zeng Y-P: Transmissibility of COVID-19 and its association with temperature and humidity. In.: Research Square; 2020.

31. Chen B, Liang H, Yuan X, Hu Y, Xu M, Zhao Y, Zhang B, Tian F, Zhu X. Roles of meteorological conditions in COVID-19 transmission on a worldwide scale. medRxiv 2020:2020.2003.2016.20037168.

32. Tosepu R, Gunawan J, Effendy DS, Ahmad LOAl, Lestari H, Bahar H, Asfian P. Correlation between weather and Covid-19 pandemic in Jakarta, Indonesia. Sci Total Environ. 2020;725:138436.

33. Ma Y, Zhao Y, Liu J, He X, Wang B, Fu S, Yan J, Niu J, Luo B. Effects of temperature variation and humidity on the mortality of COVID-19 in Wuhan. medRxiv 2020:2020.2003.2015.20036426.

34. Poole L: Seasonal Influences On The Spread Of SARS-CoV-2 (COVID19), Causality, and Forecastabililty (3-15-2020). Causality, and Forecastabililty 2020.

35. Neiderud C-J. How urbanization affects the epidemiology of emerging infectious diseases. Infect Ecol Epidemiol. 2015;5(1):27060-0. 


\section{Figures}

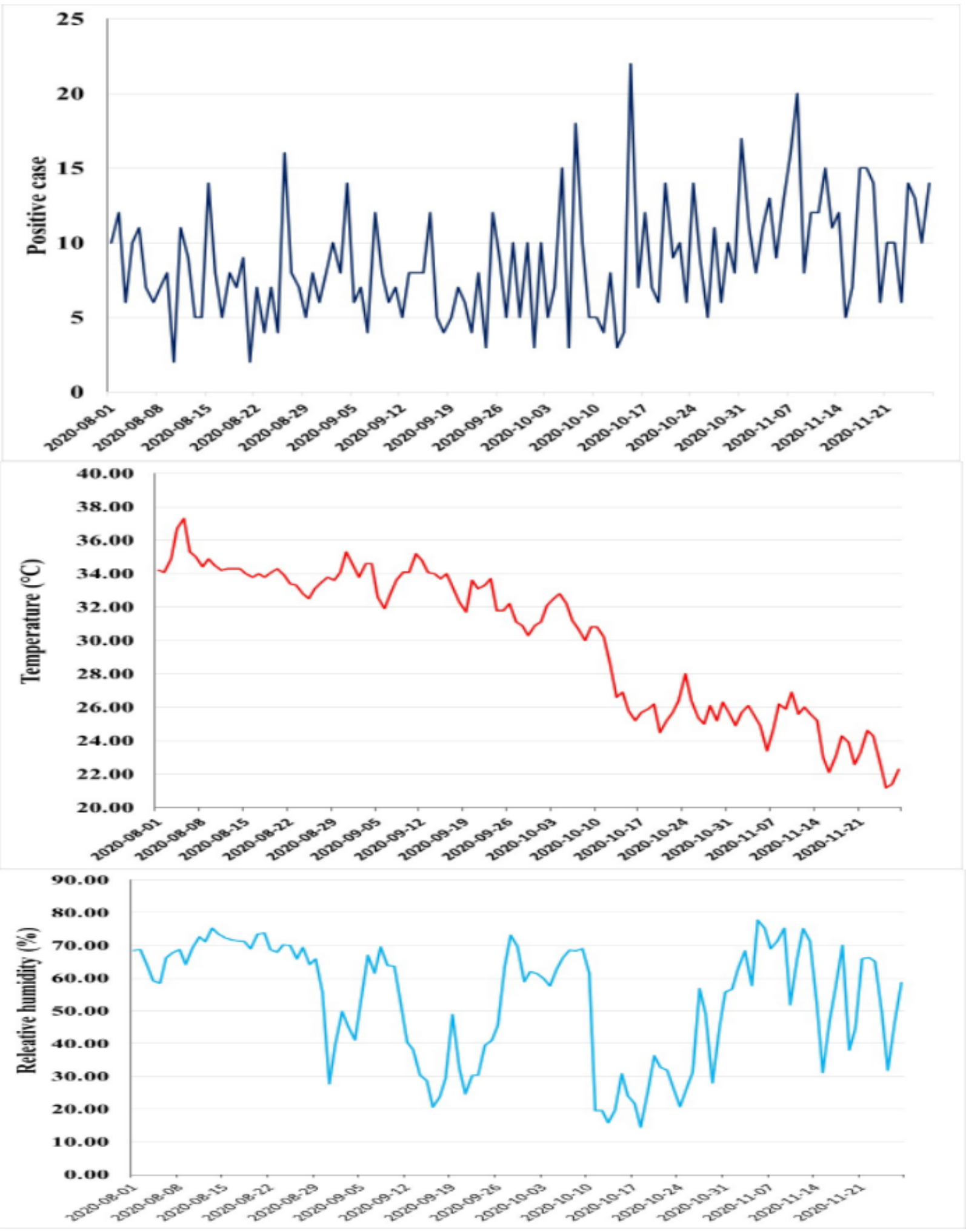

Figure 1

The positive cases of Covid-19 infection, air temperature $\left({ }^{\circ} \mathrm{C}\right)$, and relative humidity (\%) between 01 , October 2020 to 27, November 2020. 


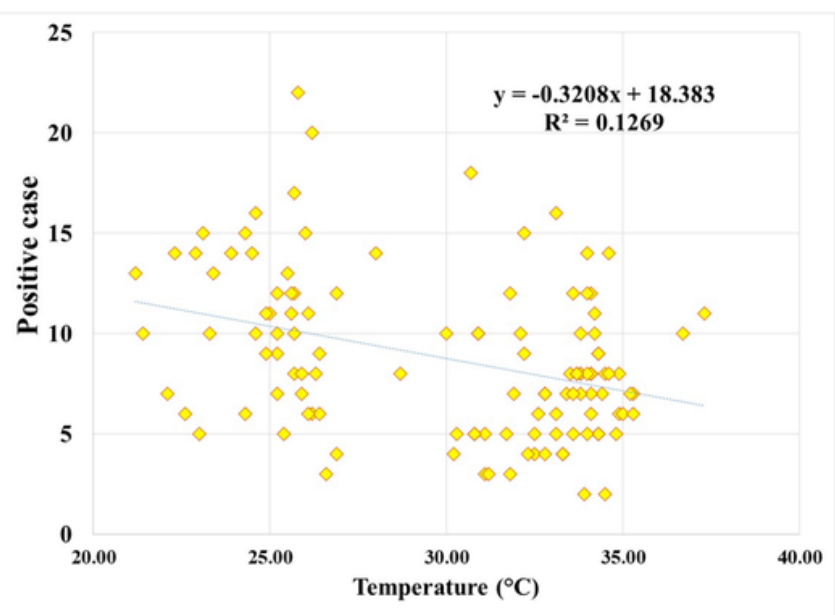

A

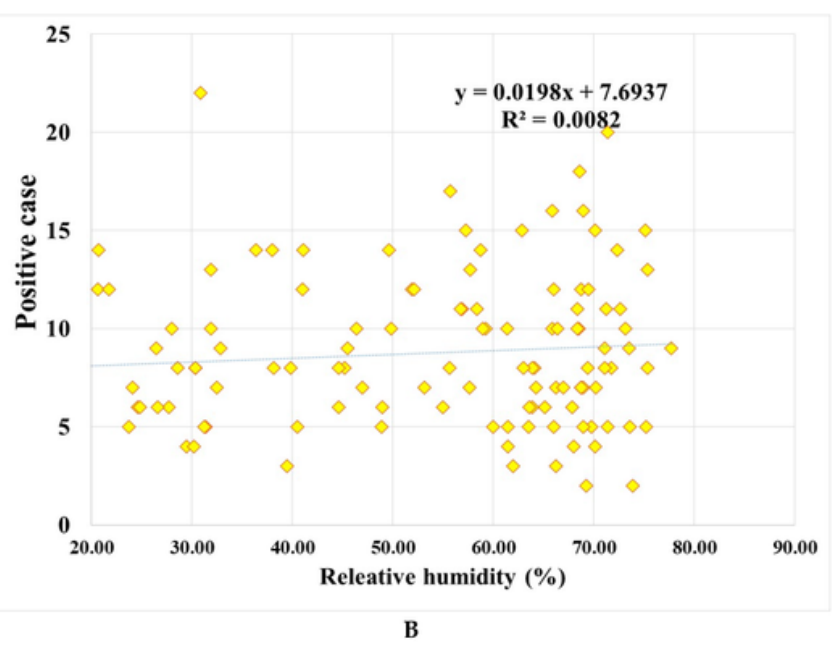

B

\section{Figure 2}

Association between positive case of SARS-CO-2 with ambient air temperature (A) and relative humidity

\section{Supplementary Files}

This is a list of supplementary files associated with this preprint. Click to download.

- Tablesupplementry.docx 